\title{
Perceptions Paysannes des Déterminants de la Faible Productivité des Ignames (Dioscorea spp) et de Leurs Niveaux de Gravité au Sud-Ouest des Savanes Sèches au Togo (Afrique de l'Ouest)
}

\section{Gnon Tchein,}

Laboratoire de Recherche sur les Agroressources et Santé Environnementale

(LARASE) Université de Lomé, Togo

Tounou Agbéko Kodjo, Agboka Komi,

Ecole Supérieure d'Agronomie (ESA), Université de Lomé, Togo

Tchao Manguilibè ,

Sanda Komla,

Laboratoire de Recherche sur les Agroressources et Santé Environnementale (LARASE), Université de Kara, Togo

Doi:10.19044/esj.2019.v15n27p256 URL:http://dx.doi.org/10.19044/esj.2019.v15n27p256

\section{Résumé}

La production extensive d'igname par la pratique de défriche brûlis occupe une place prépondérante dans les systèmes de culture au Sud-ouest des Savanes Sèches togolaises. À l'instar de l'Afrique de l'Ouest, la culture de l'igname au Togo est sujette à de nombreuses contraintes qui induisent une faible productivité des ignames et des pertes post-récolte importantes. La présente étude vise à identifier les principales causes de la baisse de de la productivité des ignames au Togo. Un diagnostic participatif avec les producteurs et les acteurs de la filière igname a été réalisé dans 27 villages de la zone à savanes sèches du Togo. La loi 80/20 et l'analyse $\mathrm{ABC}$ ont été appliquées pour l'analyse des données recueilles. Les résultats ont permis de dégager 15 principaux facteurs avec des niveaux de gravité compris entre 0,03 et 3,32. Les pertes moyennes de tubercules d'igname de consommation, de semenceaux et de leur valeur marchande, en une campagne agricole, ont, respectivement, représenté $20,62 \pm 1,86 ; 15,72 \pm 3,13 \%$ et $45,42 \pm 5,63 \%$ par hectare de 4000 buttes et par campagne agricole. La variabilité et l'instabilité des pluies, la baisse continue de la fertilité des sols et l'insuffisance de semenceaux sont perçus par les agriculteurs comme des contraintes à la production d'igname. La mitigation de ces contraintes majeures peut améliorer la production des tubercules d'igname. 
Mots clés: Savanes sèches, Productivité, Igname, Facteurs causaux, Togo

\title{
Farmer Perceptions and Severity Levels of the Determinants of Low Productivity of Yams (Dioscorea spp) in South-west Dry Savannahs in Togo (West Africa)
}

\section{Gnon Tchein,}

Laboratoire de Recherche sur les Agroressources et Santé Environnementale (LARASE) Université de Lomé, Togo

\section{Tounou Agbéko Kodjo,} Agboka Komi,

Ecole Supérieure d'Agronomie (ESA), Université de Lomé, Togo

Tchao Manguilibè,

Sanda Komla,

Laboratoire de Recherche sur les Agroressources et Santé Environnementale (LARASE), Université de Kara, Togo

\begin{abstract}
Extensive yam production by means of slash-and-burn cultivation practice holds a prominent place in the south-west of the dry savannahs of Togo cultivation systems. Like in West Africa, yam cultivation in Togo is subject to many constraints that have remained insufficiently known. These constraints lead to lower yields, and volumes of tubers in the field at postharvest, and affect the productivity of this sector. Seeking to identify the main causes of the decline in yam production or productivity in Togo, the present study has carried out a participatory diagnosis with producers and stakeholders in the yam sector in 27 villages in the dry savannah zone of Togo and has identified 15 main factors with severity levels between 0.03 and 3.32. Average losses of yam tubers, seed yield and market value in one cropping season represent $20.62 \pm 1.86,15.72 \pm 3.13 \%$ and $45.42 \pm 5.63 \%$ per hectare of 4000 mounds, respectively. The 80/20 law and the $\mathrm{ABC}$ analysis have revealed that the variability and instability of rainfall, the continuous decline of soil fertility and the insufficiency of seed are perceived by farmers as constraints to yam production. The study, therefore, indicates that mitigation of these major factors, which account for about $20 \%$ of causal factors affecting yam
\end{abstract}


productivity, can improve yam tubers production. However, the high severity of rainfall anomalies mandates future work on local perceptions of the manifestations of climatic variability and the evaluation of local practices for improving the resilience of yam cultivation in the face of climate impacts in Togo.

Keywords : Dry savanah, Productivity, Yam, Causal factors, Togo

\section{Introduction}

Plante herbacée, du genre Dioscorea spp, l'igname est beaucoup plus cultivée dans les régions tropicales humides et chaudes, d'Afrique, d'Asie et des Caraïbes où elle occupe une place très importante dans l'alimentation de millions de personnes. En Afrique de l'Ouest, elle est la deuxième plus importante plante à tubercule après le manioc. La production de 5 pays d'Afrique de l'Ouest dont le Togo représente plus de 95\% de 51 millions de tonnes métriques par an au plan mondial (Aboagye et al., 2015).

$\mathrm{Au}$ Togo, les ignames occupent la troisième place dans la production vivrière nationale après le maïs et le manioc. Elles sont cultivées notamment les cultivars appartenant au complexe D. cayenensis-rotundatadans les cinq régions économiques du pays (Ayisah et al., 2014) et jouent selon. Dansi et al. (2011) un rôle important de sécurité alimentaire et financière pour les ménages dans la société togolaise.

Mais au Togo, une baisse de production et de rendement persistent en culture d'igname sans que les causes pertinentes soient identifiées. Les symptômes d'une réduction de disponibilité de tubercules d'igname, suite à un accroissement démographique, se sont manifestés par une variation de 140,5 à 79,9 kg par personne par an de 1961-1963 à 1989-1994 (Bricas et Attaie, 1998). Au cours de la décennie passée, le rendement moyen des variétés actuellement cultivées au Togo, a décru de -0,57 par an (Milano, 2015). Au cours des dix dernières années, Aziadekey et al. (2014) signalent que la production de tubercules d'igname est de 630.000 tonnes par an et les rendements actuels oscillent entre 6 et 12 tonnes par hectare pour un potentiel de 40 t/ha pour les variétés cultivées au Togo. Le manque de nouvelles terres de forêts et de savanes plus fertiles devient de plus en plus une préoccupation majeure pour la culture d'igname dans les villages du sud-ouest des savanes sèches au Togo. Cette zone a jadis constitué une zone où la récolte de tubercules d'igname d'une campagne agricole assurait véritablement la sécurité alimentaire sur plus de douze (12) mois au sein des ménages de ses producteurs. Aujourd'hui la durée de la période de soudure est de 4 à 5 mois au sein des villages de la présente zone d'étude.

Toutefois au Togo, malgré l'importance de l'igname dans l'alimentation des togolais, très peu d'études ont été réalisées afin de mieux 
cerner les déterminants de la baisse de la productivité de l'igname. La présente étude vise donc à analyser de façon participative, les déterminants de la faible productivité des ignames dans la région des Savanes sèches du Togo et d'hiérarchiser ces facteurs selon leur niveau de gravité. Plus spécifiquement il s'agit: de recenser les perceptions des producteurs d'igname sur les contraintes majeures à la production de l'igname, de faire une évaluation de leurs niveaux de gravités.

\section{Matériel et méthodologie}

\section{Cadre de l'étude}

La zone de l'étude relève administrativement des préfectures de Bassar et Dankpen dans la partie Sud-ouest de la zone de stratification agroécologique nommée Savanes Sèches du Togo selon ITRA (2007). Elle se situe entre les parallèles $9^{\circ}$ et $9^{\circ} 50$ de latitude nord et les méridiens $0^{\circ}$ et $1^{\circ}$ de longitude est. Elle est limitée au nord par la préfecture de la Kozah, au sud par la préfecture de Sotouboua, à l'ouest par le Ghana et à l'est par la préfecture de Tchaoudjo (Figure 1). Le régime pluviométrique est unimodal et il en résulte deux saisons dont une saison pluvieuse de mai à octobre et une saison sèche de novembre à avril. Selon Atato et al, (2012), les précipitations annuelles varient entre 1000 et $1100 \mathrm{~mm}$. Les températures maximales et minimales varient entre $39^{\circ}-17^{\circ} \mathrm{C}$ en saison sèche et de $34^{\circ}-22^{\circ} \mathrm{C}$ en saison des pluies (ITRA, 2007).

Au plan écologique la zone d'étude est incluse dans la zone I des savanes sèches soudaniennes de la plaine du nord (Atato et al., 2012). La végétation est constituée principalement de soberlinia doka et I. tomentosa avec une dominance de Combretaceae (Dourma et al., 2012). Les sols ferrugineux tropicaux lessivés en surface et argileux concrétionnés ou indurés (à cuirasse ou carapace) dans l'horizon de profondeur sont dominants dans la zone de l'étude (Figure 1). Leur valeur agronomique dépend de l'importance du concrétionnement, de l'induration et de la profondeur à laquelle se manifestent ces processus. Ils sont sableux et ont une faible capacité de rétention en eau et une susceptibilité à l'érosion hydrique. Le $\mathrm{pH}$ des sols dans la zone d'étude varie d'environ 5,8 à 6,0 en surface et 5,3 à 5,6 en profondeur et leur teneur en matière organique est assez faible 0,8 à 1,5\% en surface (Mawussi, 2008). 


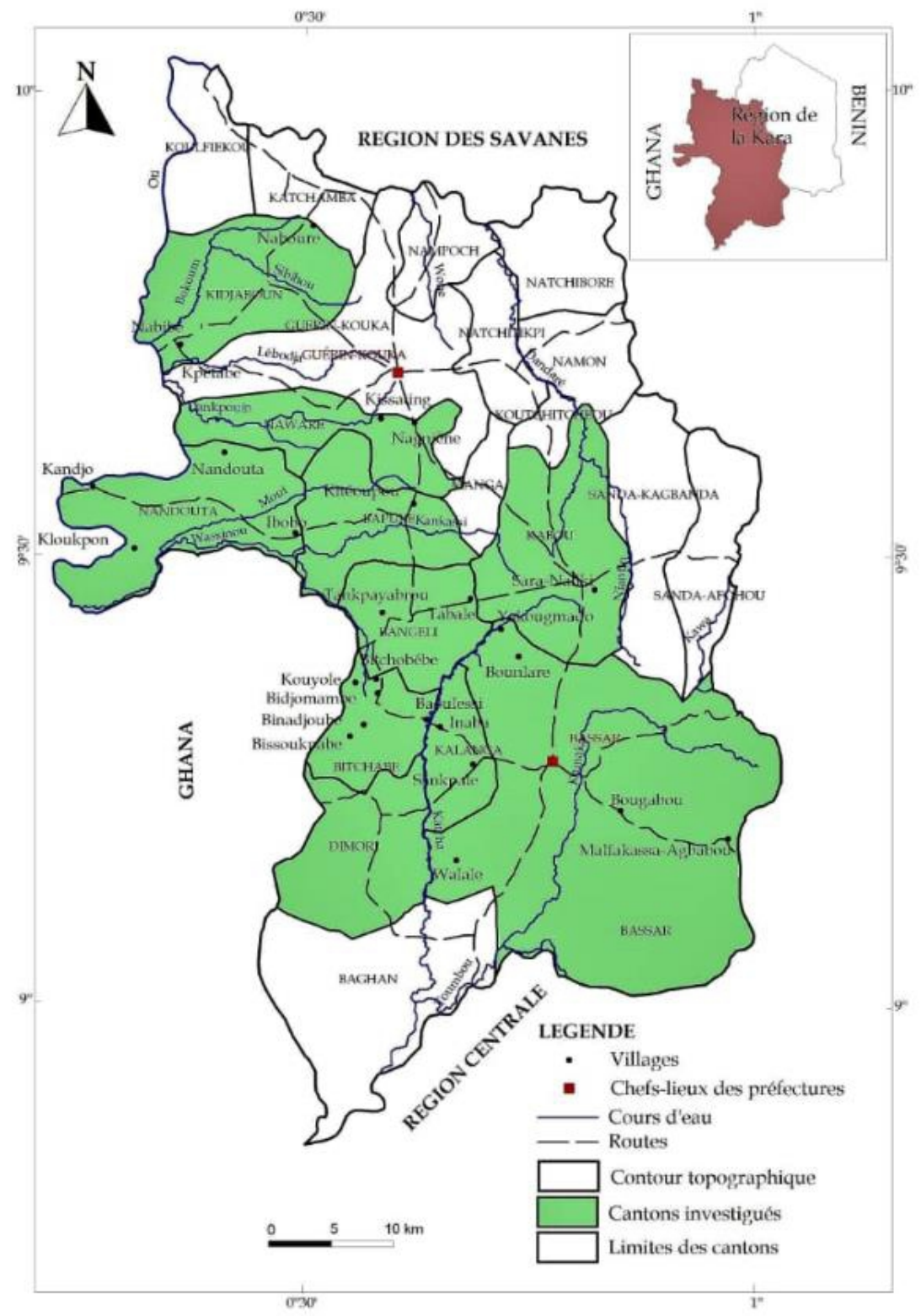

Figure 7. Carte de la zone de l'étude

Source : données de l'étude ; Sylvain et al. (1986) modifié, Conception : Gnon Tchein

\section{Approche méthodologique}

La présente étude a opté pour une démarche de co-construction des savoirs des producteurs locaux et des commerçants de tubercules d'igname. Cette approche méthodologique selon Floquet et al. (2015) offre l'avantage de partir d'une diagnostique participative avec les populations contrairement au modèle descendant classique de la recherche où les chercheurs créent, les 
vulgarisateurs diffusent et les producteurs adoptent qui est devenu caduc et permet ainsi une meilleure prise en compte des préoccupations majeures des communautés locales et donc des producteurs d'igname locaux du Sud-ouest des Savanes Sèches du Togo.

\section{Choix des villages et des ménages}

Vingt-sept (27) villages à raison de trois (3) dans chacun des neuf (9) cantons y ont été choisis du fait de leurs positions géographiques et des niveaux de production d'igname. Les critères de choix des participants retenus par village pour les entretiens de groups et les diagnostics participatifs sont entre autres : (i) de 'approche genre ; (ii) le nombre d'années d'expérience accumulé dans la culture d'igname dans le milieu de l'étude ; (iii) âge des enquêtés afin de prendre en compte toutes les groupes (jeunes, vieux); (iv) les groupes socio-culturels. Ainsi, dans chaque village une visite de prise de contacts a été faite avec le chef du village et les chefs coutumiers pour leur expliquer les objectifs et besoins de la présente étude-Cette visite a permis d'établir une liste de toutes les personnes âgées de 18 ans à 70 ans par ménages. Sous les contrôles des chefs du village, un tirage des numéros a été effectué par trois producteurs locaux d'igname et de 45 à 70 ans.

\section{Collecte des données}

\section{Facteurs explicatifs de de la baisse de la productivité et de la production d'igname}

Par village, un diagnostic participatif (Gubbels et al., 1998) basé sur l'animation d'un brainstorming appuyé par des interviews semi-structurés (ISS) de groupes et semi-dirigés au sein des deux sous-groupes préalablement constitués a été conduit. Les données ont porté sur les principales causes du faible niveau des rendements et la baisse de la production des ignames.

Après des travaux de synthèses graduelles en sous-groupes et par village, la liste d'un ensemble de facteurs causaux a été provisoirement établie. La méthode des «5 pourquoi» (Determine the root cause: 5 whys : iSixSigma$\underline{\text { Editorial) }}$ a été également utilisée pour mieux comprendre les mécanismes d'actions des effets de divers facteurs causaux sur la culture de l'igname et a permis de retenir 15 facteurs principaux.

A la suite de l'identification des différents facteurs, une typologie de ces derniers a été faite par la technique de construction du diagramme de Venn (Sandifer, 2004). Grace ainsi à la méthode des 5 pourquoi (axée sur le regroupement des éléments de chaque typologie, les relations entre les différents facteurs ont été établies et montrant une arborescence de causalités entretenant la baisse de la productivité et de la production des tubercules d'igname. En revanche, les facteurs causaux selon les producteurs ont différents impacts dans les champs. A cet effet, le critère choisi pour les 
comparer a été le score de gravité de leurs effets. Pour la présente étude, la gravité d'un facteur en culture d'igname est l'ensemble des conséquences que les divers effets de ce dernier peuvent potentiellement avoir sur la diminution de volume et de qualité des tubercules d'igname produits engendrant par ricochet une perte d'argent aux acteurs de la filière igname. Cette gravité est quantifiée par une valeur pondérale.

\section{Détermination de la distribution de niveaux de gravité des variables de priorisation des facteurs causaux de la baisse de production en culture d'igname}

Trois (03) différentes variables ont été déterminées et calculées par les formules suivantes:

- la gravité moyenne d'un facteur causal $\left(\mathrm{G}_{\mathrm{m}}\right)$ dans les villages de son recensement est calculée par la formule $\left(\mathrm{G}_{\mathrm{m}}\right)=\left(\mathrm{Sg}_{1}+\mathrm{Sg}_{2}+\ldots \ldots+\mathrm{Sg}_{\mathrm{n}-}\right.$ $\left.{ }_{1}+\mathrm{Sg}_{\mathrm{n}}\right) / \mathrm{NG}$, avec $\mathrm{Sg}_{1}$ : score de gravité du facteur causal dans le village 1; $\mathrm{Sg}_{2}$ : score de gravité du facteur causal dans le village $2 ; \mathrm{Sg}_{\mathrm{n}-1}$ : score de gravité du facteur causal dans le village $\mathrm{n}-1 ; \mathrm{Sg}_{\mathrm{n}}$ : score de gravité du facteur causal dans le village n; et NG: nombre total de villages de relevés de scores de gravité du facteur causal.

- la Gravité Cumulée des effets des facteurs causaux $\left(\mathrm{G}_{\mathrm{c}}\right)$ par la formule $:\left(G_{c}\right)=\left[\left(G_{m f 1}+\left(G_{m f 1}+G_{m f 2}\right)+\ldots . .+\left(G_{m f n-1}+G_{m f n}\right)\right]\right.$ et

- le pourcentage de Gravités des effets Cumulés des facteurs causaux $\left(G_{\mathrm{c}(\%)}\right)=\mathrm{G}_{\mathrm{c}} / \mathrm{G}_{\mathrm{t}} \%,=\left(\mathrm{G}_{\mathrm{mf} 1} / \mathrm{G}_{\mathrm{t}} \%+\left(\mathrm{G}_{\mathrm{mf} 1+} \mathrm{G}_{\mathrm{mf} 2)} / \mathrm{G}_{\mathrm{t}} \%+\ldots .+\left(\mathrm{G}_{\mathrm{mfn}-1}+\right.\right.\right.$ $\mathrm{G}_{\mathrm{mfn})} / \mathrm{G}_{\mathrm{t}} \%$ avec, $\mathrm{G}_{\mathrm{mf} 1}$ :score moyen de gravité du facteur causal 1; $\mathrm{G}_{\mathrm{mf} 2}$ : score moyen de gravité du facteur causal $2 ; \mathrm{G}_{\mathrm{mfn}-1}$ : score moyen de gravité du facteur causal $n-1 ; \mathrm{G}_{\mathrm{mfn}}$ : score moyen de gravité du facteur causal $n$ et $\mathrm{G}_{\mathrm{t}}$ : Gravité totale de tous les facteurs causaux recensés.

Il a été donc facile de se baser sur les variables liées aux niveaux de gravités qui sont quantifiées pour tracer la courbe de Pareto.

\section{Analyses statistiques}

Les statistiques descriptives c'est-à-dire les es moyennes et pourcentages des données issues des synthèses des interviews semi-structurés (ISS) de groupes et semi-dirigés ont été réalisées à l'aide du logiciel SPSS 21.1 (Statistical Package for the Social Sciences) version 2016. Les données quantitatives portant sur les scores moyens de gravité des facteurs causaux ont été ensuite soumises à une analyse de la variance (ANOVA) à l'aide du même logiciel. Les comparaisons des moyennes ont été réalisées avec le test de Student Newman-Keuls (au seuil de 5\% SNK). Les moyennes issues de l'analyse cette analyse ont servis à une priorisation des facteurs causaux recensés grâce â la loi 80/20 (Hardy, 2010 et Amar, 2014). 
Pour réaliser la courbe de Pareto, dans un tableau à cinq colonnes, les facteurs causaux ont été classés dans l'ordre décroissant des valeurs de leurs scores moyens de gravités, des gravités cumulées, des pourcentages des effets cumulés et des $80 \%$ de la loi Pareto.

La courbe de Pareto couplée à l'analyse ABC (Alcouffe, 2002 ; Chauvey et Naro, 2004) a permis de repérer et diviser les facteurs causaux en trois classes :

- la classe A : 20\% de facteurs causaux ont été responsables $80 \%$ des effets dommageables ;

- la classe B : 30\% des facteurs causaux ont été responsables de $15 \%$ des effets de baisse de la productivité et de la production des tubercules.

- la classe C: $50 \%$ des facteurs causaux inventoriés n'ont été responsables que $5 \%$ de diminution de la productivité et de la production de tubercules d'igname.

\section{Résultats}

\section{Facteurs causaux menaçant la productivité et la production des tubercules d'igname et leur typologie}

Les résultats de cette étude ont permis de dégager 15 facteurs causaux de la baisse de la productivité et de la production des tubercules d'igname au Sud-ouest des Savanes Sèches du Togo. Il y avait cinquante (50) ans, les niveaux de gravités moyennes de ces facteurs ont été moindres comparés à ceux des (10) dernières années (Tableau 1). Toutefois, les exigences du tuteurage des plants ont montré une gravité supérieure il y a cinquante ans par rapport aux dix (10) dernières années $(0,46 \pm 0,04$ contre $0,24 \pm 0,01)$. Près de $90 \%$ des producteurs de plus de 45 ans de l'ensemble des villages de cette étude ont pu expliquer cette supériorité par le fait que le tuteurage avait toujours constitué une des pratiques ancestrales d'entretiens des champs d'igname. Il contribuait à libérer de l'espace entre les buttes pour des associations polyculturales et polyspécifiques. A cette époque, des arbustes sur les parcelles à défricher et à butter ainsi que la main d'œuvre familiale étaient disponibles et facilitaient le tuteurage systématique de chaque plant d'igname. Car de l'avis des producteurs locaux d'igname, le tuteurage a jadis été nécessaire pour assurer une bonne récolte de tubercules. Au cours des trois dernières décennies, la raréfaction de jachères relativement longues et le déboisement avancé ne permettaient plus un bon développement des arbustes. Le producteur est obligé d'aller loin de son champ et sans l'aide de ses enfants que la scolarisation a rendus moins disponibles pour la recherche de tuteurs. Ainsi, tout producteur d'igname des temps présents ne s'adonne qu'au tuteurage des plants de certains cultivars qu'il juge par expérience en être exigeants. Cette nouvelle appréciation a conduit 30 à $50 \%$ des plants sans tuteurs dans les champs d'igname. La précocité de chute des feuilles de plants 
d'igname a toujours existé et a été traduite par des scores de gravité quasi identiques $(0,07 \pm 0,02$ et $0,07 \pm 0,00$ au Tableau 1$)$. La pression foncière et la pénurie temporelle de tubercules ont une gravité très insignifiante il y a cinquante (50) ans qu'à présent selon la perception d'un peu plus de 50\% des producteurs actuels dans $100 \%$ des villages prospectés (respectivement $0,02 \pm$ 0,00 et $0,01 \pm 0,00$ contre $0,07 \pm 0,01$ et $0,45 \pm 0,03$ ). Unanimement les coûts élevés de la main d'œuvre ont présenté une gravité moyenne de 0,24 $\pm 0,02$ dans le passé (il y a 50 ans). Ils étaient payés sous la forme de travail dans les opérations de défrichement et de buttage durant deux à quatre campagnes agricoles consécutives contre une fille en mariage. Au cours des dix (10) dernières années ces coûts sont financièrement payés aux ouvriers agricoles pour les mêmes opérations et ont eu un score moyen de gravité plus élevé de $0,37 \pm 0,01$. Les recueils et la mise en cohérence des explications des producteurs locaux ont permis de regrouper ces facteurs en sept (07) catégories dont les contraintes/facteurs climatiques changement climatique, l'agronomie, dégâts des bioagresseurs, le stockage et conservation, la pression foncière, la sociologie et aux pratiques cultuelles (Tableau 1).

Les résultats ont montré que les exploitations subissent une conjugaison des contraintes. ors des séances de brainstorming, les participants ont unanimement signalé que les anomalies pluviométriques occasionnent annuellement des périodes sèches qui perturbent le bon développement des plants d'igname. Au sein des exploitations agricoles, plus de 50\% des producteurs ont à des périodes variables de 3 à 5 ans, manqué de semenceaux pour continuer les champs d'ignames. En revanche, pour plus $70 \%$ des interviwés, la pression foncière au cours des dix (10) dernières années dans $56 \%$ des villages dont Binadjoube, Kissating, Kandjo et Yacougmado, ne permet plus aux anciens producteurs d'igname d'étendre leur champ ni aux nouveaux de commencer une culture d'igname lorsqu'ils ont du matériel de plantation. Les producteurs de tubercules dans les villages ont unanimement affirmé que, dans le meilleur des cas, la durée de la jachère ne peut dépasser trois ans. Les sols sont cultivés en permanence et l'exigence de l'igname en tête de culture n'est plus possible depuis plus de deux décennies. Au plan sociologique, près de $75 \%$ des interviewers ont estimé que dans 30 à $50 \%$ des champs d'igname et dans près de $70 \%$ des villages de l'étude, les tubercules de consommation récoltés ou non et les semenceaux sont volés à plus de $10 \%$ de planteurs chaque année. Ils ont indiqué qu'annuellement un producteur peut perdre par canton tout son matériel de plantation et ne plus être en mesure de continuer sa culture d'igname. Selon plus de $70 \%$ des producteurs locaux interviwés, $12 \%$ des semenceaux plantés seraient volés dans les buttes aux passages des peulhs qui sont en nomadisme avec leurs troupeaux de bœufs. Ces bœufs dévastent des stocks d'igname dans les champs causant des conflits parfois mortels entre éleveurs et producteurs d'igname. Au plan cultuel, dans 
$80 \%$ des villages du diagnostic participatif, au moins $50 \%$ des producteurs d'igname ont dénoncé des vols par déplacements mystiques de rendement d'un champ vers celui du voleur. Les résultats de l'étude ont révélé l'existence de pratiques de sorcellerie qui ont empêché qu'il pleuve dans les champs de leurs ennemis : c'est la rétention mystique de la pluie.

Tableau 1. Typologie de facteurs causaux de la baisse de la productivité et production de tubercules d'igname et leurs niveaux de gravités moyennes pour les années 1968 et 2018 au Sud-ouest des Savanes Sèches au Togo

Facteurs causaux

Typologie

Climatique

Agronomique

Dégâts des bioagresseurs
Scores moyens de gravité depuis il y a

\begin{tabular}{llcc}
\hline Climatique & Anomalies pluviométriques & $1,28 \pm 0,06 \mathrm{c}$ & $3,32 \pm 0,10 \mathrm{a}$ \\
& Baisse de la fertilité & $0,53 \pm 0,05 \mathrm{~d}$ & $2,81 \pm 0,04 \mathrm{~b}$ \\
& Feux de brousse & $0,07 \pm 0,01 \mathrm{~h}$ & $0,07 \pm 0,00 \mathrm{~g}$ \\
& Enherbement des champs d'igname & $0,26 \pm 0,02 \mathrm{f}$ & $0,67 \pm 0,04 \mathrm{~d}$ \\
Agronomique & Insuffisance de semenceaux & $0,05 \pm 0,01 \mathrm{f}$ & $1,01 \pm 0,07 \mathrm{c}$ \\
& Exigence de tuteurage des plants & $0,46 \pm 0,04 \mathrm{e}$ & $0,24 \pm 0,01 \mathrm{f}$ \\
& Coûts élevés de la main d'œuvre & $0,24 \pm 0,02 \mathrm{f}$ & $0,37 \pm 0,01 \mathrm{e}$ \\
Dégâts des & Courte durée de stockage de tubercules & $0,04 \pm 0,01 \mathrm{~h}$ & $0,39 \pm 0,02 \mathrm{e}$ \\
bioagresseurs & & & \\
& Attaques parasitaires & $0,04 \pm 0,01 \mathrm{~h}$ & $0,16 \pm 0,02 \mathrm{~g}$ \\
& Précocité de chute de feuilles & $0,07 \pm 0,02 \mathrm{~h}$ & $0,07 \pm 0,00 \mathrm{~h}$ \\
& Attaques de termites & $0,07 \pm 0,02 \mathrm{~h}$ & $0,03 \pm 0,00 \mathrm{~h}$ \\
$\begin{array}{l}\text { Distribution de la } \\
\text { production }\end{array}$ & Pénurie temporelle de tubercules & $0,01 \pm 0,00 \mathrm{~h}$ & $0,07 \pm 0,01 \mathrm{~h}$ \\
Pression foncière & Pression foncière & & \\
Sociologique & Vols de tubercules aux champs & $0,02 \pm 0,00 \mathrm{~h}$ & $0,45 \pm 0,03 \mathrm{e}$ \\
Cultuelle & Rétention mystique de la pluie & $0,12 \pm 0,02 \mathrm{~h}$ & $0,10 \pm 0,01 \mathrm{~g}$ \\
\hline
\end{tabular}

${ }^{*}$ Gravité a été dans le cas du présent travail, un ensemble de conséquences dommageables d'un facteur causal sur la productivité et la production en tubercules d'igname. **Année 1968, ****année 2018 sont des années de référence des niveaux de gravité des facteurs causaux. Les moyennes d'une même colonne suivies de lettres différentes sont significativement différentes au test de Student Newman-Keuls au seuil de 5\%.

\section{Arborescence du problème de baisse de productivité et de production en culture d'igname}

Les résultats des séances de construction participative des Diagrammes de Venn ont permis de mettre en relation la baisse de la productivité et de la production des tubercules d'igname avec les facteurs causaux qui l'ont engendré (Figure 2). Il s'agit d'un ensemble complexe de facteurs causaux ne dépendant pas forcément tous les uns des autres. Au niveau des sous facteurs causaux de l'anomalie pluviométrique, les résultats n'ont pas permis de conclure que les poches de sécheresse sont dues au retard de démarrage de la saison des pluies ni aux fins précoces de la saison des pluies encore moins aux trop fortes chaleurs ambiantes. La baisse de la fertilité des sols de la culture d'igname n'a pas montré de lien causal évident avec les vols de tubercules ni 
avec leurs pourritures rapides identifiées qui ont conduit à de courtes durées de stockage. Elles ont souvent conduit à des pénuries temporelles de tubercules empêchant d'assurer les repas des ouvriers agricoles.

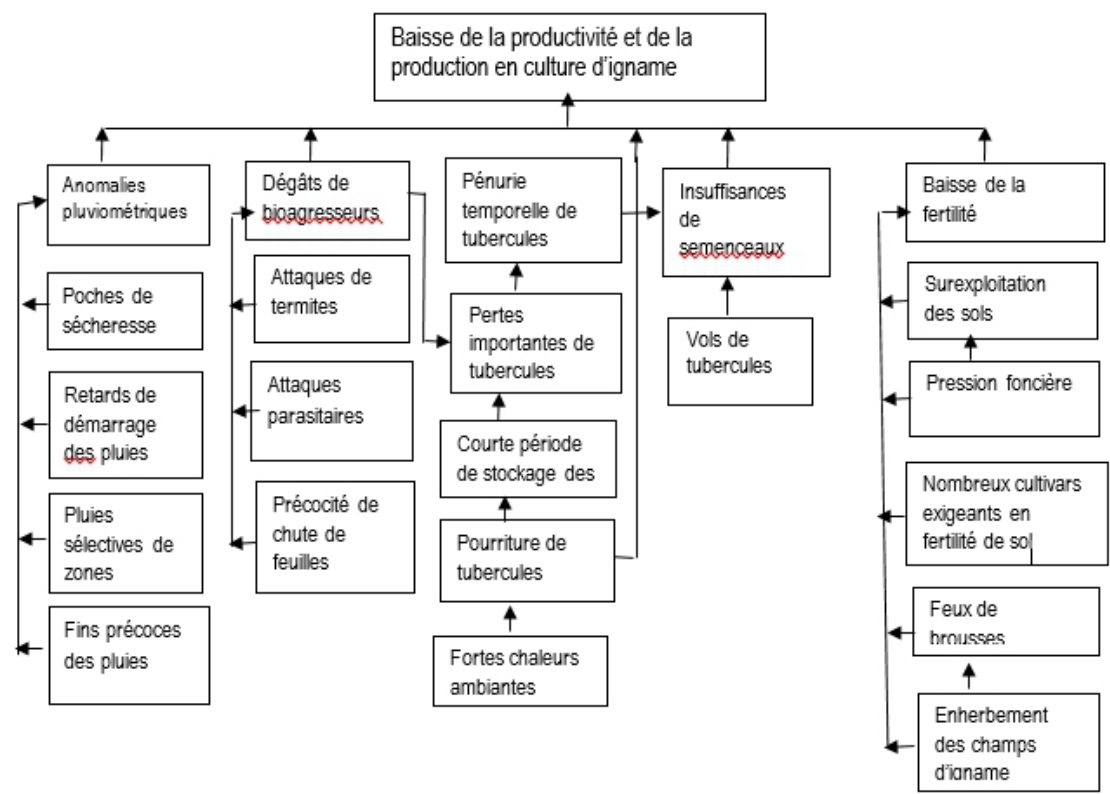

Figure 8. Arborescence des facteurs causaux induisant la baisse de la productivité et de la production des tubercules d'igname au Sud-ouest des Savanes Sèches au Togo.

Les effets des facteurs causaux ont des impacts qu'une échelle de gravité permettra de mesurer leurs niveaux d'intensité.

Impacts des facteurs causaux recensés et détermination d'une échelle d'évaluation du niveau de gravité de leurs conséquences dommageables à la baisse de productivité de tubercule d'igname

Les résultats des conséquences dommageables ont été identifiés à travers trois variables : les pertes de tubercules de consommation, pertes de semenceaux et pertes de valeurs marchandes induites et chiffrées respectivement à $20,62 \pm 1,86 ; 15,72 \pm 3,13 \%$ et $45,42 \pm 5,63 \%$ par hectare de 4000 buttes en général. Cependant les valeurs la plus faible et la plus élevée de ces pertes en tubercules de consommation, en semenceaux et en valeur marchande ont respectivement varié de 17,86 $\pm 1,10 ; 12,75 \pm 1,92$ et 38,26 \pm 3,70 dans le canton de Bassar à 21,96 $\pm 1,25 ; 19,48 \pm 4,88$ et $51,80 \pm 7,65$ dans celui de Bitchabe (Tableau 2). Des avis des producteurs et commerçants de tubercules, la fragmentation et les blessures des tubercules au cours des récoltes et lors de leurs transports les ont conduits à de courtes périodes de stockage. Les valeurs moyennes de toutes les catégories de pertes chiffrées ont été plus alarmistes suivants les perceptions des participants pessimistes (35\% dans tous les 27 villages). En revanche celles des optimistes ont été plus faibles 
(15\% dans tous les 27 villages). En éléments explicatifs, les optimistes ont affirmé que les pertes des tubercules de consommation ont toujours été plus importantes que celles des semenceaux. Pour eux, un tubercule d'igname subit un pourrissement progressif ce qui permet à la partie non encore pourrie d'être préservée par une taille et servir de semenceaux ou de cossette qui pourra être également vendu.

Tableau 2. Pertes dues aux effets de 15 facteurs causaux en culture d'igname selon les perceptions des producteurs locaux dans 9 cantons au Sud-ouest des Savanes Sèches au

Togo

\begin{tabular}{|l|c|c|c|}
\hline \multirow{2}{*}{ Cantons } & \multicolumn{3}{|c|}{ Pertes moyennes au cours d'une campagne agricoles $(\% \pm \mathrm{ES})^{*}$} \\
\cline { 2 - 4 } & $\begin{array}{c}\text { Tubercules de } \\
\text { consommation }\end{array}$ & Semenceaux & Valeurs marchandes \\
\hline Bapuré & $19,87 \pm 1,07 \mathrm{~b}$ & $14,54 \pm 0,79 \mathrm{ab}$ & $43,01 \pm 1,13 \mathrm{ab}$ \\
\hline Bangéli & $21,37 \pm 0,29 \mathrm{a}$ & $15,57 \pm 0,70 \mathrm{ab}$ & $46,17 \pm 0,70 \mathrm{~b}$ \\
\hline Bassar & $17,86 \pm 1,10 \mathrm{c}$ & $12,75 \pm 1,92 \mathrm{ab}$ & $38,26 \pm 3,70 \mathrm{ab}$ \\
\hline Bitchabe & $21,96 \pm 1,25 \mathrm{a}$ & $19,48 \pm 4,88 \mathrm{~b}$ & $51,80 \pm 7,65 \mathrm{~cd}$ \\
\hline Kabou & $21,64 \pm 0,17 \mathrm{a}$ & $16,32 \pm 0,53 \mathrm{ab}$ & $47,46 \pm 0,87 \mathrm{~b}$ \\
\hline Kalanga & $20,57 \pm 0,38 \mathrm{ab}$ & $15,88 \pm 0,66 \mathrm{ab}$ & $45,57 \pm 0,69 \mathrm{~b}$ \\
\hline Kidjaboun & $21,07 \pm 1,61 \mathrm{a}$ & $15,21 \pm 0,40 \mathrm{ab}$ & $45,35 \pm 2,03 \mathrm{~b}$ \\
\hline Nandouta & $21,32 \pm 0,94 \mathrm{a}$ & $15,82 \pm 0,49 \mathrm{ab}$ & $46,43 \pm 1,65 \mathrm{~b}$ \\
\hline Naware & $19,93 \pm 1,00 \mathrm{~b}$ & $15,90 \pm 0,53 \mathrm{ab}$ & $44,78 \pm 1,91 \mathrm{ab}$ \\
\hline
\end{tabular}

*Les moyennes d'une même colonne suivies de lettres différentes sont significativement différentes au test de Newman-Keuls au seuil de 5\%.

Echelle d'évaluation de niveaux de gravité des conséquences dommageables des facteurs causaux de baisse de productivité de tubercule d'igname

Les résultats des séances d'attribution des scores de gravité aux facteurs causaux responsables de la baisse de la productivité et la production des tubercules d'igname ont permis d'élaborer une échelle de valeurs pondérales (Tableau 3). Elle a été constituée de trois colonnes définissant de la gauche vers la droite, cinq classes de scores de gravité qui ont varié au plan pondéral de $0-2$ à $8-10$, les caractéristiques des pertes liées aux conséquences des effets des facteurs causaux et cinq typologies de niveaux d'acceptabilité des ampleurs des pertes survenues. 
Tableau 3. Eléments d'une échelle d'évaluation de la gravité des impacts des facteurs causaux de la baisse de la productivité et de la production en culture d'igname au Sud-ouest des Savanes Sèches au Togo

\begin{tabular}{|l|l|l|}
\hline $\begin{array}{c}\text { Classes de } \\
\text { scores de } \\
\text { gravité }\end{array}$ & $\begin{array}{l}\text { Caractéristiques des conséquences des effets de } \\
\text { facteurs causaux de faible productivité en culture } \\
\text { d'igname* }\end{array}$ & $\begin{array}{c}\text { Typologies de } \\
\text { gravité }\end{array}$ \\
\hline 0 à 2 & $\begin{array}{l}\text { Dessèchement de moins de } 12,5 \% \text { de tubercules de } \\
\text { consommation (5 calebasses) et de 10\% du matériel de } \\
\text { plantation de mauvaise qualité phytosanitaire. }\end{array}$ & Faible \\
\hline 2 à 4 & $\begin{array}{l}\text { Pertes de 12,5 à 20\% (5 à } 8 \text { calebasses) de tubercules et } \\
\text { une valeur marchande réduite de 10\% par rapport à la } \\
\text { campagne agricole antérieure ; 20\% matériel de } \\
\text { plantation de mauvaise qualité phytosanitaire. }\end{array}$ & $\begin{array}{l}\text { Modérée/ } \\
\text { Supportable }\end{array}$ \\
\hline 4 à 6 & $\begin{array}{l}\text { Pertes de plus de 20 à 37,5\% de tubercules de } \\
\text { consommation (8 à 15 « calebasses » de tubercules); 10 } \\
\text { à 20\% de matériel de plantation et faibles calibres des } \\
\text { tubercules d'une valeur marchande réduite de 10\% par } \\
\text { rapport à la campagne précédente. }\end{array}$ & Sévère/Sérieux \\
\hline 6 à 8 & $\begin{array}{l}\text { Pertes de 37,5 à 50\% de tubercules de consommation, } \\
50 \% \text { de matériel de plantation; valeur marchande } \\
\text { réduite de 20\% par rapport à la campagne agricole } \\
\text { précédente. }\end{array}$ & Très grave \\
\hline 8 à 10 & $\begin{array}{l}\text { Pertes de plus de 20 « calebasses » (50\%) de tubercules } \\
\text { de consommation d'igname, 50\% de perte de matériel } \\
\text { de plantation et 30\% de valeur marchande des } \\
\text { tubercules vendus. }\end{array}$ & Inacceptable. \\
\hline
\end{tabular}

*Mesure locale de 100 tubercules d'igname souvent destinés à la vente.

\section{Distribution des variables liées à la gravité des facteurs causaux de la baisse de production en culture d'igname}

Les Tableaux $4 \mathrm{a}$ et $4 \mathrm{~b}$ présentent les résultats moyens de deux variables liées à la baisse de la productivité et de la production de tubercules d'igname et qui sont : la gravité cumulée et le pourcentage des effets cumulés de gravités des facteurs causaux. Elles ont été calculées sur la base des scores de gravités attribués par les producteurs, vendeurs et transformateurs de tubercules d'igname en foufou selon les perceptions et expériences locales des aléas dommageables à la filière igname. Dans l'ensemble, les notes moyennes d'appréciation des effets cumulés de gravité d'un facteur causal à un autre lorsqu'on s'élève dans les rangs supérieurs de leurs niveaux d'intégration ont été de plus en plus élevées $(2,88 \pm 0,28$ à $10,00 \pm 0,00)$. Les résultats sur la mesure des gravités cumulées des quinze (15) facteurs causaux ont été distribués selon les cantons et ceux des anomalies pluviométriques ont montré des différences significatives $(\mathrm{p}<0,05)$ entre les moyennes notamment à Bitchabé $(2,95 \pm 0,07$ à $10,00 \pm 0,00)$, Kalanga $(2,88 \pm 0,28$ à $10,00 \pm 0,00)$ et Kidjaboun $(4,28 \pm 0,22$ à $10,00 \pm 0,00)$. Les moyennes des cumuls de gravité des effets des facteurs causaux successifs ont été statistiquement identiques 
$(10,00 \pm 0,00)$ dans tous les neuf (09) cantons de la zone des présents travaux à partir du facteur causal coûts élevés de la main d'œuvre (Tableau 4a). Pour les pourcentages des effets cumulés des facteurs causaux, les résultats sur les moyennes des trois (03) facteurs causaux : feux de brousse, précocité de chute de feuilles et attaques des termites ont été statistiquement identiques $(98,85 \pm$ $0,11$ à $100,00 \pm 0,00)$ dans tous les neuf (09) cantons de la zone d'étude au seuil de 5\% (du test SNK) (Tableau 4b). Concernant la gravité cumulée des effets des facteurs et du pourcentage des effets cumulés, les Tableaux $4 \mathrm{a}$ et $4 \mathrm{~b}$ ont permis d'identifier qu'en moyenne les valeurs ont respectivement variées de 3,32 à 10 et de 33,20 à 100\%. Les comparaisons des éléments d'une de ces deux variables entre eux ne peuvent avoir de sens. Chaque facteur intègre sa gravité à celle de l'autre en fonction des impacts d'effets variés que chacun peut disposer en vue d'une nocivité plus accrue de l'ensemble sur la productivité et à la production de l'igname. 
Tableau 4a. Mesures des gravités cumulées des facteurs causaux de baisse de la productivité et de la production de l'igname dans neuf (09) cantons au Sud-ouest des Savanes Sèches au Togo

\begin{tabular}{|c|c|c|c|c|c|c|c|c|c|}
\hline \multirow[t]{2}{*}{ Facteurs causaux } & \multicolumn{9}{|c|}{ Cantons (moyenne $\pm \mathrm{ES}$ )* } \\
\hline & Bangéli & Bapuré & Bassar & Bitchabe & Kabou & Kalanga & Kidjaboun & Nandouta & Naware \\
\hline $\begin{array}{l}\text { Anomalies } \\
\text { pluviométriques }\end{array}$ & $3,41 \pm 0,13 \mathrm{c}$ & $3,01 \pm 0,27 \mathrm{c}$ & $3,20 \pm 0,18 c$ & $2,95 \pm 0,07 \mathrm{c}$ & $3,38 \pm 0,04 \mathrm{c}$ & $2,88 \pm 0,28 \mathrm{~d}$ & $4,28 \pm 0,22 \mathrm{~d}$ & $3,19 \pm 0,11 \mathrm{c}$ & $3,53 \pm 0,07 \mathrm{c}$ \\
\hline Baisse de la fertilité & $6,29 \pm 0,13 b c$ & $5,98 \pm 0,09 \mathrm{bc}$ & $5,95 \pm 0,23 \mathrm{bc}$ & $5,81 \pm 0,08 \mathrm{bc}$ & $6,27 \pm 0,20 \mathrm{c}$ & $5,40 \pm 0,22 \mathrm{c}$ & $7,01 \pm 0,19 \mathrm{c}$ & $5,97 \pm 0,07 \mathrm{bc}$ & $6,40 \pm 0,06 \mathrm{c}$ \\
\hline $\begin{array}{ll}\text { Insuffisance } & \text { de } \\
\text { semenceaux }\end{array}$ & $7,16 \pm 0,01 \mathrm{~b}$ & $7,18 \pm 0,15 b$ & $6,95 \pm 0,22 b$ & $6,86 \pm 0,03 \mathrm{~b}$ & $7,22 \pm 0,06 \mathrm{bc}$ & $6,83 \pm 0,30 b$ & $7,46 \pm 0,13 \mathrm{bc}$ & $7,19 \pm 0,11 b$ & $7,37 \pm 0,03$ bc \\
\hline $\begin{array}{l}\text { Enherbement des champs } \\
\text { d'igname }\end{array}$ & $7,81 \pm 0,02 b$ & $7,79 \pm 0,10 b$ & $7,74 \pm 0,19 b$ & $7,46 \pm 0,07 \mathrm{ab}$ & $7,75 \pm 0,14 b$ & $7,83 \pm 0,17 \mathrm{ab}$ & $8,04 \pm 0,12 b$ & $7,80 \pm 0,14 b$ & $7,99 \pm 0,06 b$ \\
\hline Pression foncière & $8,26 \pm 0,08 \mathrm{~b}$ & $8,20 \pm 0,05 \mathrm{ab}$ & $8,11 \pm 0,15 \mathrm{~b}$ & $8,26 \pm 0,12 \mathrm{ab}$ & $8,24 \pm 0,17 \mathrm{~b}$ & $8,24 \pm 0,13 \mathrm{ab}$ & $8,41 \pm 0,12 \mathrm{ab}$ & $8,23 \pm 0,13 \mathrm{ab}$ & $8,31 \pm 0,04 \mathrm{~b}$ \\
\hline $\begin{array}{l}\text { Courte durée de stockage } \\
\text { de tubercules }\end{array}$ & $8,67 \pm 0,15 a b$ & $8,54 \pm 0,07 \mathrm{ab}$ & $8,50 \pm 0,18 a b$ & $8,68 \pm 0,08 \mathrm{ab}$ & $8,68 \pm 0,19 a b$ & $8,58 \pm 0,23 a b$ & $8,75 \pm 0,06 \mathrm{ab}$ & $8,63 \pm 0,11 \mathrm{ab}$ & $8,79 \pm 0,01 \mathrm{ab}$ \\
\hline $\begin{array}{l}\text { Exigence de tuteurage } \\
\text { des plants }\end{array}$ & $9,05 \pm 0,17 \mathrm{ab}$ & $8,95 \pm 0,07 a$ & $8,85 \pm 0,21 \mathrm{a}$ & $9,08 \pm 0,08 \mathrm{ab}$ & $9,06 \pm 0,17 \mathrm{ab}$ & $8,94 \pm 0,24 \mathrm{ab}$ & $9,05 \pm 0,03 \mathrm{a}$ & $9,00 \pm 0,10 \mathrm{a}$ & $9,15 \pm 0,02 \mathrm{a}$ \\
\hline $\begin{array}{l}\text { Coûts élevés de la main } \\
\text { d'œuvre }\end{array}$ & $9,29 \pm 0,13 \mathrm{a}$ & $9,21 \pm 0,04 \mathrm{a}$ & $9,12 \pm 0,20 \mathrm{a}$ & $9,29 \pm 0,09 a$ & $9,23 \pm 0,11 \mathrm{a}$ & $9,18 \pm 0,18 \mathrm{a}$ & $9,29 \pm 0,01 \mathrm{a}$ & $9,28 \pm 0,09 a$ & $9,40 \pm 0,01 \mathrm{a}$ \\
\hline $\begin{array}{l}\text { Rétention mystique de la } \\
\text { pluie }\end{array}$ & $9,54 \pm 0,12 \mathrm{a}$ & $9,44 \pm 0,02 \mathrm{a}$ & $9,34 \pm 0,16 a$ & $9,45 \pm 0,06 \mathrm{a}$ & $9,50 \pm 0,07 \mathrm{a}$ & $9,47 \pm 0,15 a$ & $9,54 \pm 0,02 \mathrm{a}$ & $9,49 \pm 0,07 a$ & $9,62 \pm 0,01 \mathrm{a}$ \\
\hline Attaques parasitaires & $9,72 \pm 0,06 \mathrm{a}$ & $9,64 \pm 0,03 \mathrm{a}$ & $9,53 \pm 0,11 \mathrm{a}$ & $9,62 \pm 0,05 \mathrm{a}$ & $9,66 \pm 0,03 \mathrm{a}$ & $9,72 \pm 0,02 \mathrm{a}$ & $9,66 \pm 0,01 \mathrm{a}$ & $9,69 \pm 0,03 \mathrm{a}$ & $9,71 \pm 0,04 \mathrm{a}$ \\
\hline $\begin{array}{l}\text { Vols de tubercules aux } \\
\text { champs }\end{array}$ & $9,81 \pm 0,04 \mathrm{a}$ & $9,77 \pm 0,01 \mathrm{a}$ & $9,64 \pm 0,10 a$ & $9,73 \pm 0,04 \mathrm{a}$ & $9,78 \pm 0,02 \mathrm{a}$ & $9,79 \pm 0,02 \mathrm{a}$ & $9,74 \pm 0,02 \mathrm{a}$ & $9,79 \pm 0,02 \mathrm{a}$ & $9,79 \pm 0,03 a$ \\
\hline $\begin{array}{l}\text { Pénurie temporelle de } \\
\text { tubercules }\end{array}$ & $9,85 \pm 0,04 \mathrm{a}$ & $9,85 \pm 0,02 \mathrm{a}$ & $9,79 \pm 0,04 a$ & $9,82 \pm 0,02 \mathrm{a}$ & $9,83 \pm 0,01 \mathrm{a}$ & $9,84 \pm 0,01 \mathrm{a}$ & $9,80 \pm 0,03 \mathrm{a}$ & $9,83 \pm 0,02 \mathrm{a}$ & $9,85 \pm 0,04 \mathrm{a}$ \\
\hline Feux de brousse & $9,90 \pm 0,02 \mathrm{a}$ & $9,91 \pm 0,01 \mathrm{a}$ & $9,88 \pm 0,02 \mathrm{a}$ & $9,89 \pm 0,01 \mathrm{a}$ & $9,90 \pm 0,01 \mathrm{a}$ & $9,89 \pm 0,01 \mathrm{a}$ & $9,90 \pm 0,02 \mathrm{a}$ & $9,89 \pm 0,01 \mathrm{a}$ & $9,88 \pm 0,04 \mathrm{a}$ \\
\hline $\begin{array}{l}\text { Précocité de chutes de } \\
\text { feuilles }\end{array}$ & $9,96 \pm 0,00 \mathrm{a}$ & $9,97 \pm 0,01 \mathrm{a}$ & $9,96 \pm 0,01 \mathrm{a}$ & $9,96 \pm 0,01 \mathrm{a}$ & $9,97 \pm 0,00 \mathrm{a}$ & $9,96 \pm 0,01 \mathrm{a}$ & $9,97 \pm 0,01 \mathrm{a}$ & $9,97 \pm 0,01 \mathrm{a}$ & $9,97 \pm 0,01 \mathrm{a}$ \\
\hline Attaques de termites & $10,00 \pm 0,00 \mathrm{a}$ & $10,00 \pm 0,00 a$ & $10,00 \pm 0,00 \mathrm{a}$ & $10,00 \pm 0,00 \mathrm{a}$ & $10,00 \pm 0,00 \mathrm{a}$ & $10,00 \pm 0,00 \mathrm{a}$ & $10,00 \pm 0,00 \mathrm{a}$ & $10,00 \pm 0,00 \mathrm{a}$ & $10,00 \pm 0,00 a$ \\
\hline
\end{tabular}

*Les moyennes d'une même colonne suivies de lettres différentes sont significativement différentes

(test de Student-Newman-Keuls au seuil de 5\%) 
Tableau $4 \boldsymbol{b}$. Mesures des pourcentages des effets cumulés des facteurs causaux de baisse de productivité et de la production de l'igname dans neuf (09) cantons au Sud-ouest des Savanes Sèches au Togo

\begin{tabular}{|c|c|c|c|c|c|c|c|c|c|}
\hline \multirow[t]{2}{*}{ Facteurs causaux } & \multicolumn{9}{|c|}{ Cantons (moyenne $\pm \mathrm{ES}$ )* } \\
\hline & Bangéli & Bapuré & Bassar & Bitchabe & Kabou & Kalanga & Kidjaboun & Nandouta & Naware \\
\hline $\begin{array}{l}\text { Anomalies } \\
\text { pluviométriques }\end{array}$ & $34,09 \pm 1,29 \mathrm{~g}$ & $29,64 \pm 3,10 \mathrm{~g}$ & $32,08 \pm 1,75 \mathrm{~g}$ & $29,45 \pm 0,73 \mathrm{~g}$ & $33,77 \pm 0,36 \mathrm{~g}$ & $28,90 \pm 2,80 \mathrm{fg}$ & $43,50 \pm 1,56 \mathrm{~g}$ & $31,93 \pm 1,09 \mathrm{~g}$ & $35,32 \pm 0,71 \mathrm{~g}$ \\
\hline Baisse de la fertilité & $62,94 \pm 1,34$ ef & $\begin{array}{c}57,88 \pm 2,18 \\
\text { ef }\end{array}$ & $59,23 \pm 3,06$ ef & $57,73 \pm 0,92$ ef & $62,73 \pm 1,97 \mathrm{f}$ & $55,92 \pm 3,99 \mathrm{f}$ & $71,04 \pm 1,47$ ef & $59,68 \pm 0,72 \mathrm{f}$ & $64,01 \pm 0,60$ ef \\
\hline $\begin{array}{l}\text { Insuffisance de } \\
\text { semenceaux }\end{array}$ & $71,55 \pm 0,13 \mathrm{e}$ & $69,91 \pm 2,01 \mathrm{de}$ & $69,23 \pm 3,87 \mathrm{e}$ & $68,24 \pm 0,55 \mathrm{e}$ & $72,18 \pm 0,58 \mathrm{e}$ & $70,25 \pm 3,48$ ef & $76,07 \pm 1,77 \mathrm{e}$ & $71,90 \pm 1,08 \mathrm{de}$ & $73,71 \pm 0,33 \mathrm{e}$ \\
\hline $\begin{array}{l}\text { Enherbement des champs } \\
\text { d'igname }\end{array}$ & $77,87 \pm 0,46 \mathrm{de}$ & $78,24 \pm 1,31 \mathrm{~d}$ & $77,08 \pm 2,15 \mathrm{~d}$ & $75,21 \pm 1,58 \mathrm{~d}$ & $78,2 \pm 0,60 \mathrm{~d}$ & $77,98 \pm 1,51 \mathrm{~d}$ & $80,35 \pm 1,24 \mathrm{de}$ & $78,79 \pm 1,14 \mathrm{~d}$ & $79,62 \pm 0,17 \mathrm{~d}$ \\
\hline Pression foncière & $82,43 \pm 0,64 d$ & $82,29 \pm 0,74 \mathrm{~d}$ & $80,83 \pm 1,82 \mathrm{~d}$ & $82,62 \pm 1,17 \mathrm{~cd}$ & $83,06 \pm 0,85 \mathrm{~cd}$ & $82,44 \pm 1,27 \mathrm{~d}$ & $84,15 \pm 1,21 \mathrm{~d}$ & $83,09 \pm 0,98 \mathrm{~d}$ & $83,03 \pm 0,30 \mathrm{~cd}$ \\
\hline $\begin{array}{l}\text { Courte durée de stockage } \\
\text { de tubercules }\end{array}$ & $86,5 \pm 1,07 \mathrm{~cd}$ & $85,74 \pm 0,65 \mathrm{~cd}$ & $84,72 \pm 2,11 \mathrm{dc}$ & $86,84 \pm 0,77 \mathrm{c}$ & $87,5 \pm 1,12 \mathrm{c}$ & $85,77 \pm 2,35 \mathrm{c}$ & $87,55 \pm 0,64 \mathrm{c}$ & $87,08 \pm 0,72 \mathrm{~cd}$ & $87,93 \pm 0,66 \mathrm{c}$ \\
\hline $\begin{array}{l}\text { Exigence de tuteurage } \\
\text { des plants }\end{array}$ & $90,72 \pm 1,48 \mathrm{c}$ & $89,57 \pm 0,69 \mathrm{~cd}$ & $88,5 \pm 2,07 \mathrm{c}$ & $90,76 \pm 0,77 \mathrm{bc}$ & $90,73 \pm 1,21 \mathrm{bc}$ & $89,38 \pm 2,37 \mathrm{bc}$ & $90,54 \pm 0,32 \mathrm{bc}$ & $90,78 \pm 0,56 \mathrm{c}$ & $91,62 \pm 0,78 \mathrm{bc}$ \\
\hline $\begin{array}{l}\text { Coûts élevés de la main } \\
\text { d'œuvre }\end{array}$ & $92,92 \pm 1,29 \mathrm{bc}$ & $92,15 \pm 0,43 \mathrm{~b}$ & $91,2 \pm 2,02 b$ & $92,85 \pm 0,91 \mathrm{bc}$ & $92,4 \pm 0,59 \mathrm{bc}$ & $91,84 \pm 1,78 b$ & $92,89 \pm 0,15 \mathrm{bc}$ & $93,53 \pm 0,55 \mathrm{bc}$ & $94,11 \pm 0,64 \mathrm{~b}$ \\
\hline $\begin{array}{l}\text { Rétention mystique de la } \\
\text { pluie }\end{array}$ & $95,42 \pm 1,15 \mathrm{abc}$ & $94,42 \pm 0,26 \mathrm{ab}$ & $93,38 \pm 1,57 \mathrm{~b}$ & $94,54 \pm 0,57 \mathrm{~b}$ & $95,04 \pm 0,73 \mathrm{~b}$ & $94,68 \pm 1,49 \mathrm{~b}$ & $95,41 \pm 0,22 \mathrm{~b}$ & $95,71 \pm 0,51 \mathrm{~b}$ & $96,38 \pm 0,47 \mathrm{ab}$ \\
\hline Attaques parasitaires & $97,17 \pm 0,62 \mathrm{ab}$ & $96,44 \pm 0,33 \mathrm{ab}$ & $95,3 \pm 1,14 \mathrm{ab}$ & $96,22 \pm 0,49 \mathrm{ab}$ & $96,64 \pm 0,26 \mathrm{ab}$ & $97,19 \pm 0,19 \mathrm{ab}$ & $96,63 \pm 0,02 \mathrm{ab}$ & $96,98 \pm 0,36 \mathrm{ab}$ & $97,37 \pm 0,08 \mathrm{ab}$ \\
\hline $\begin{array}{l}\text { Vols de tubercules aux } \\
\text { champs }\end{array}$ & $98,13 \pm 0,40 \mathrm{ab}$ & $97,73 \pm 0,10 \mathrm{ab}$ & $96,45 \pm 1,02 \mathrm{ab}$ & $97,23 \pm 0,39 a b$ & $97,82 \pm 0,22 \mathrm{ab}$ & $97,92 \pm 0,22 \mathrm{ab}$ & $97,43 \pm 0,18 \mathrm{ab}$ & $97,84 \pm 0,31 \mathrm{ab}$ & $98,31 \pm 0,01 \mathrm{a}$ \\
\hline $\begin{array}{l}\text { Pénurie temporelle de } \\
\text { tubercules }\end{array}$ & $98,47 \pm 0,36 \mathrm{a}$ & $98,45 \pm 0,18$ a & $97,95 \pm 0,38 \mathrm{a}$ & $98,1 \pm 0,15 \mathrm{ab}$ & $98,28 \pm 0,15 \mathrm{a}$ & $98,36 \pm 0,13 \mathrm{a}$ & $98,03 \pm 0,28$ a & $98,25 \pm 0,28 \mathrm{a}$ & $98,82 \pm 0,11 \mathrm{a}$ \\
\hline Feux de brousse & $99 \pm 0,19 \mathrm{a}$ & $99,13 \pm 0,08 \mathrm{a}$ & $98,85 \pm 0,17 \mathrm{a}$ & $98,85 \pm 0,11 \mathrm{a}$ & $98,98 \pm 0,11 \mathrm{a}$ & $98,94 \pm 0,06 \mathrm{a}$ & $98,95 \pm 0,18 \mathrm{a}$ & $98,94 \pm 0,29 a$ & $99,15 \pm 0,11 \mathrm{a}$ \\
\hline $\begin{array}{l}\text { Précocité de chutes de } \\
\text { feuilles }\end{array}$ & $99,63 \pm 0,02 \mathrm{a}$ & $99,69 \pm 0,06 \mathrm{a}$ & $99,63 \pm 0,10 \mathrm{a}$ & $99,56 \pm 0,08 \mathrm{a}$ & $99,74 \pm 0,05 \mathrm{a}$ & $99,58 \pm 0,08 \mathrm{a}$ & $99,66 \pm 0,05 \mathrm{a}$ & $99,62 \pm 0,14 \mathrm{a}$ & $99,71 \pm 0,06 \mathrm{a}$ \\
\hline Attaques de termites & $100,00 \pm 0,00 \mathrm{a}$ & $100,00 \pm 0,0 \mathrm{a}$ & $100,00 \pm 0,00 \mathrm{a}$ & $100,00 \pm 0,00 \mathrm{a}$ & $100,00 \pm 0,00 \mathrm{a}$ & $100,00 \pm 0,00 \mathrm{a}$ & $100,00 \pm 0,00 \mathrm{a}$ & $100,00 \pm 0,00 \mathrm{a}$ & $100,00 \pm 0,00 \mathrm{a}$ \\
\hline
\end{tabular}

*Les moyennes d'une même colonne suivies de lettres différentes sont significativement différentes (test de Student-Newman-Keuls au seuil de 5\% 


\section{Priorisation des facteurs causaux de baisse de la productivité et production de tubercules d'igname}

Les analyses des données suivant les distributions de Pareto ou loi de Pareto ont révélé des résultats (Figure 3). Suivant cette loi, les anomalies pluviométriques, la baisse continue de la fertilité des sols et l'insuffisance des semenceaux pour couvrir les surfaces emblavées soit $20 \%$ de tous les 15 facteurs causaux inventoriés ont été responsables de $71,50 \%$ des effets dommageables en culture d'igname dans la zone de l'étude. L'analyse ABC a été ensuite appliquée et mis en place trois groupes de facteurs causaux classés par ordre décroissant d'effets dommageables A, B et C. Le groupe A a été constitué des $20 \%$ des facteurs causaux identifiés, occasionnant 71,50\% des conséquences cumulés dans la perte de rendement en tubercules d'igname. Le groupe B a représenté 33,33\% des facteurs causaux responsables de 21,20\% des effets cumulés. Ils ont été moins névralgiques que ceux de A mais plus que ceux de C. En revanche $46,67 \%$ des facteurs causaux relevant de la catégorie $\mathrm{C}$, ont induit le plus faible taux d'effets dommageables en production des tubercules d'igname soit 7,30\%. L'ensemble des facteurs causaux identifiés appartiennent à une gamme diversifiée dont les variabilités climatiques ont présenté le niveau de gravité le plus élevé $(3,32)$ sur une échelle de gravité (valeur) allant de 0 à 10 et qui a servi à quantifier et à apprécier les conséquences dommageables de chacun d'eux. Quant aux facteurs causaux de la catégorie $\mathrm{C}$, ils présentent des scores de gravité variant de 0,03 à 0,23 et ont des impacts négligeables sur la réduction de la production et de la productivité de l'igname au Sud-ouest des Savanes Sèches au Togo.

Les résultats de l'analyse $\mathrm{ABC}$ ont montré que plus les facteurs causaux regroupés, croissent numériquement, moins les conséquences des effets ont été importantes. Au plan d'éventuels apports de solutions, la justification économique de ces résultats de la présente étude indique en urgence une intervention dans l'ordre $\mathrm{A}>\mathrm{B}>\mathrm{C}$ pour que soient relevées la productivité et la production des tubercules d'igname. Les facteurs causaux du groupe $\mathrm{A}$ ont été statistiquement indiqués très graves $(71,50 \%$ de conséquences cumulées) suivant les lois de probabilités de Pareto. Toutefois, les 5 du groupe $\mathrm{B}$ ont des effets contraignants moindres à la productivité et à la production de tubercules d'igname. En revanche les 7 facteurs causaux regroupés en $\mathrm{C}$ ont des effets mineurs et sans quasiment aucune répercussion négative dans la productivité et la production de l'igname dans la zone de notre étude. 


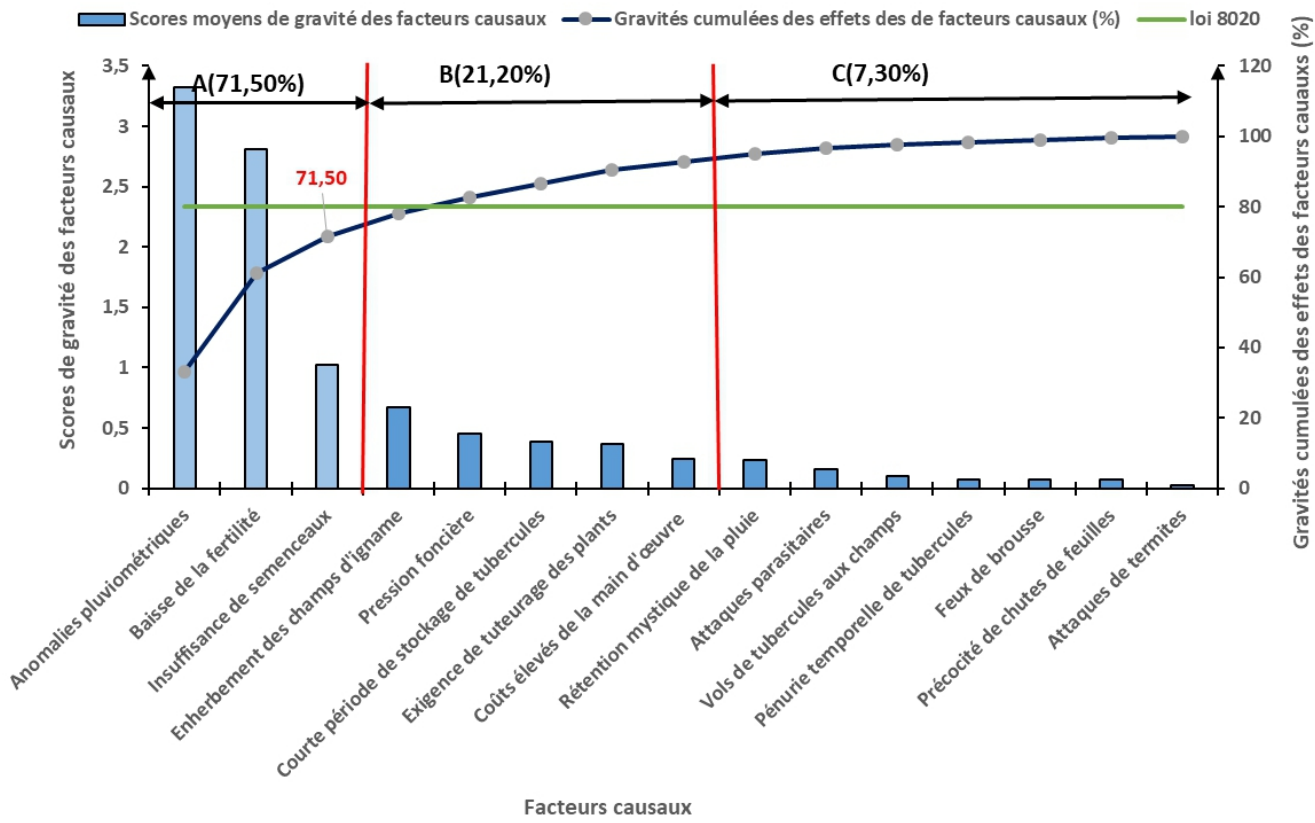

Figure 9. Mise en évidence par la loi 80/20 et l'analyse ABC d'une priorisation de trois facteurs causaux responsabes de la baisse de la productivité et de la production en culture d'igname au Sud-ouest des Savanes Sèches au Togo.

\section{Discussion}

15 facteurs causaux répartis en sept catégories ont été inventoriés comme responsable de la baisse de la productivité et de la production de la culture de l'igname au Sud-ouest des Savanes Sèches au Togo. Parmi eux, les anomalies pluviométriques, la baisse continue de la fertilité des sols et l'insuffisance de semenceaux sont les principaux facteurs causaux retenus suivant la loi 80/20. Ils diffèrent de ceux de Dansi et al. (2013) qui portent sur 19 contraintes dont les principales sont : les dégâts d'insectes sur les feuilles et les tubercules, les attaques de nématodes sur les tubercules, la sécheresse la pauvreté des sols et le flétrissement. Cette différence pourrait s'expliquer par l'aspect conceptuel de nos travaux basés sur l'inventaire des facteurs causaux de cette baisse dans une zone limitée sur l'ouest de deux préfectures. Les impacts de gravité cumulée des effets de ces principaux facteurs causaux ont été importants et chiffrés à 71,50\% et ayant contribué aux pertes de tubercules de consommation, pertes de semenceaux et pertes de valeurs marchandes. Les présents résultats sont très proches d'autres travaux antérieurs (Onkendi et al., 2014 ; Navia et al., 2017). Les dégâts des bioagresseurs incluant les attaques de cochenilles, des termites, des nématodes et les facteurs causaux des pourritures qui sont perçus par les producteurs locaux de la présente étude. Quoique ces facteurs causaux se retrouvent dans la catégorie $C$, leurs dégâts 
entretiennent annuellement la pénurie temporelle de tubercules et les producteurs n'en disposent plus pour assurer les repas des ouvriers agricoles lors des opérations de défrichement et de buttage. Les responsabilités des nématodes dans les lésions importantes sur les racines et tubercules d'igname, des pertes de poids et de la valeur marchande des tubercules d'igname et du pouvoir germinatif des semences et les galles des tubercules sont connus et rapportées par plusieurs auteurs (Sikora et Fernández, 2005 ; Nicol et al., 2011; Onkendi et al., 2014 ; Navia et al., 2017). Les exigences du tuteurage pour certains cultivars sont incriminées par plus de $75 \%$ des producteurs locaux de cette étude et corroborent ceux de Hahn (1993) qui révèle que la lutte contre les maladies foliaires de l'igname justifie l'exigence du tuteurage. L'enherbement rapide et important est également dommageable à la récolte au point d'obtenir un score de gravité qui varie de 1 à 2 respectivement pour les années 1968 et 2018 selon les résultats de cette étude. De nos jours, c'est devenu une connaissance objective que grâce aux actions de la Rubisco, les plantes ont une capacité photosynthétique mais celle-ci diffère entre les espèces. Ainsi les adventices en disposent donc et du fait qu'elles poussent dans un même champ, peuvent être mycorhizées par des souches spécifiques de champignons mycorhiziens arbusculaires (CMA). Cette symbiose avec les CMA peut les rendre plus résilientes parce que disposant de l'eau et des éléments nutritifs venant des CMA et peuvent se développer mieux et plus rapidement pour prendre le dessus sur les plants d'igname cultivés d'ailleurs sans apport de fertilisant. Ceci confirme plusieurs travaux antérieurs pour lesquels l'enzyme responsable de la fixation de carbone dans tout organisme capable de photosynthèse est la Rubisco (Andersson et Backlund, 2008 ; Hauser et al., 2015), qui catalyse la conversion de $\mathrm{CO}_{2}$ estimée à $10^{11}$ tonnes annuellement en matière organique (Hauser et al., 2015). Pour Tournebize et al. (2012), la maîtrise manuelle de l'enherbement en cultures d'ignames est coûteuse en temps de travail (entre 250 et $750 \mathrm{~h}$ de travail par hectare).

Les résultats de l'étude mettent en évidence une arborescence de cinq (05) lots de facteurs causaux de réduction de la productivité de l'igname cultivée. Cette arborescence serait des niveaux différents d'intégrations ascendantes de chaque facteur causal recensé pour en constituer chacun des 5 lots identifiés. L'ensemble constituerait des maillons dont chaque niveau croissant d'intégration pourrait donner une intensité de nocivité nouvelle et plus grande dans la réduction de la productivité et de la production de l'igname. Mais il existerait également dans l'arborescence certains facteurs qui agiraient seuls (hors des lots). Ainsi, les fins précoces des pluies n'auraient aucune action synergique avec les pluies sélectives de zones à arroser ni avec les retards de pluies ou les poches de sécheresse qui sont tous des éléments constitutifs des anomalies pluviométriques. Soro et al. (2010) et Dansi et al. (2011) ont rapporté que la production de l'igname est confrontée à d'énormes 
contraintes (les attaques des maladies et des ravageurs, la pauvreté des sols, la sécheresse et dans certaines régions les excès d'humidité en cas d'excès de pluie, etc.) qui sont à la base d'énormes pertes de rendement et d'érosion génétique. Nos résultats corroborent partiellement avec les leurs si leurs contraintes agissent isolément.

Les pertes moyennes de tubercules, de semenceaux et de valeurs marchandes occasionnées par les facteurs causaux rapporté dans la présente étude, sont en pourcentage respectivement de 20,62;15,72 et 45,42 par hectare de 4000 buttes d'igname. Ces pertes seraient probablement dues à une réduction de pouvoir germinatif de certains semenceaux, les cas de pourritures de semenceaux et tubercules dans les buttes et en stocks et aussi à des cas de dessèchement de certains jeunes plants. Ces dégâts peuvent être causés par la résultante de dégâts occasionnés par des facteurs biotiques et abiotiques dont les cas de vols de tubercules mentionnés par cette étude. L'ampleur des pertes figurant sur l'échelle ne diffère pas de celles relevées par plusieurs travaux scientifiques antérieurs. Selon Lancaster et Coursey (1984), l'igname de même que d'autres racines et tubercules comme le manioc et le taro, subit des pertes post-récoltes élevées qui fluctuent entre 25 et $60 \%$. Spécifiquement, Hahn (1993) et Soro et al. (2010) lient la baisse de qualité après récolte, sa valeur marchande et la faible productivité de l'igname à la pression des insectes ravageurs et les maladies y compris les viroses (surtout Yam mosaic virus) relevées par plusieurs auteurs dont au Togo, Ayisah et Gumedzoe (2012) font mention d'un potentiel de pathogénicité élevée dû aux virus de la mosaïque de l'igname. Selon Yao et al. (2017) en Côte d'Ivoire, trois mois après la plantation, la prévalence de l'anthracnose a varié de 4 à 72,22 \% et la sévérité de 1 à 4. Ces niveaux d'appréciation de la gravité des bioagresseurs sont plus élevés que ceux des résultats de cette étude et pourraient être expliqués par le fait que les producteurs locaux peuvent ne pas avoir de connaissances sur la gravité de toutes les maladies de l'igname. Pour Ouédraogo (2012) les analyses de sensibilité montrent que les paysans perdront $93 \%$ de leurs revenus suite à une augmentation de la température de $5^{\circ} \mathrm{C}$. Car pour N'drin et al. (2019), les cultivateurs, en plus des nombreux problèmes auxquels ils sont déjà confrontés, doivent désormais faire face à ce nouveau phénomène de changements climatiques. Il en résulte donc une insuffisance de semenceaux rapporté par les présents travaux et dénoncées unanimement par plusieurs travaux antérieurs (Dansi et al., 2011 et Baco et al., 2013).

De l'ensemble des niveaux de gravités évalués au cours de cette étude, les résultats présentent une échelle de mesure de la gravité des effets des facteurs dommageables en un tableau de trois colonnes dont la première a révélé cinq (05) classes de scores de gravité qui varient de 0-2 à 8-10. Elles correspondent chacune dans la seconde colonne à des taux de pertes allant de 
$12,5 \%$ en tubercules de consommation et $10 \%$ de matériel de plantation sur la première ligne à plus de $50 \%$ en tubercules de consommation et de matériel de plantation et $30 \%$ de perte de valeur marchande par rapport à la campagne agricole antérieure sur la cinquième ligne. Elles se correspondent dans la troisième colonne à cinq (05) typologies de gravité allant de faible à inacceptable. Ces typologies traduisent des niveaux d'acceptabilité des dommages en culture d'igname. Ainsi les pertes supérieures à $50 \%$ de tubercules ou à 30\% de valeur marchande perdues, compromettent la poursuite de la culture de l'igname au cours de la prochaine campagne agricole. Une telle gravité a été jugée inacceptable selon les producteurs et commerçants de tubercules d'igname sur l'échelle élaborée. Ceci indiquerait que c'est à l'utilisateur de l'échelle d'affecter des scores de gravité en tenant compte de ses connaissances validées scientifiquement objectives sur le potentiel impactant du facteur qu'il met en cause. En exemple, l'utilisateur peut juger de la gravité d'un retard dans l'exécution de travaux sur le calendrier agricole d'une zone donnée qu'en connaissance de cause et rester par exemple en accord avec les résultats de Lacointe et al. (1987) selon lesquels pour Dioscorea alata, plus tardive est la plantation entre juillet et novembre, plus courte est la phase végétative et plus réduits sont les rendements en tubercules. Pour l'expert, l'évaluation de dégâts potentiels des facteurs causaux tiendra rigoureusement compte de plusieurs paramètres de nocivité de facteurs afin d'anticiper sur une mauvaise récolte à venir.

Parmi les variables liées à la gravité des facteurs causaux recensés, le pourcentage de gravités des effets cumulés des facteurs causaux a varié de 33,20 à $100 \%$ dont $71,50 \%$ sont dues aux anomalies pluviométriques, la baisse continue de la fertilité des sols et l'insuffisance des semenceaux réunis. Ce pourcentage de $71,50 \%$ confirme l'importante responsabilité des trois facteurs causaux mentionnés dans la criticité totale des facteurs recensés. Les pertes de tubercules, de semenceaux et de leur valeur marchande moyenne de $35 \%$ corroborent avec ceux de Queneherve (1997) qui estime les pertes de récolte de tubercules d'igname dues aux nématodes de par le monde entre 30 à $40 \%$.

La priorisation des facteurs causaux de baisse de la productivité et production de tubercules d'igname indique trois classes $\mathrm{A}, \mathrm{B}$ et $\mathrm{C}$ dont la classe A regroupe $20 \%$ de facteurs causaux statistiquement la plus préoccupante qui nécessite des actions immédiates d'atténuation tandis que la classe $\mathrm{B}$ est d'une importance moyenne et doit nécessiter des actions à moyen terme et celle de la $\mathrm{C}$ est statistiquement insignifiante et donc négligeable. Selon nos connaissances actuelles, ces priorités ainsi classées pour l'action diffèrent des travaux antérieurs (Dansi et al., 2013) mais viennent en complément à ces derniers. Néanmoins les contenus des classes $\mathrm{A}$ et $\mathrm{B}$ se rapprochent en partie de ceux de Tournebize et al. (2012) dans l'enherbement des champs d'igname puis de Baco et al. (2013) sur l'insuffisance et la 
mauvaise qualité du matériel de plantation. Tous ont conforté l'oscillation de rendements entre 6 et 12 tonnes par hectare pour un potentiel de 40 t/ha au Togo (Aziadekey et al., 2014). Ceci implique que la mitigation des trois facteurs de la classe A ainsi délimités s'impose avant celle des cinq facteurs de la classe B en production de tubercules d'igname au Sud-ouest des Savanes Sèches au Togo.

\section{Conclusion}

Les résultats montrent que 15 facteurs sont responsables de la baisse de la productivité en culture d'igname au sud-ouest des savanes sèches au Togo. Ils sont priorisés en en trois groupes dont le A est constitué de $20 \%$ des facteurs dont la gravité cumulée de leurs effets contribuent principalement à $71,50 \%$ à la baisse de la productivité de l'igname dans la zone de l'étude. Le B se composent de $33 \%$ des facteurs dont les impacts sont moyens et réduisent cette productivité à hauteur de $21,20 \%$ mais le C est constitué de $45,66 \%$ de facteurs dont les impacts sont négligeables. Le groupe A reste préoccupant et la mitigation de ses facteurs peut améliorer la productivité de l'igname. Toutes fois l'utilisation de l'échelle de gravité mise en place par cette étude peut renforcer de manière prédictive, l'atténuation rationnelle des effets des principaux facteurs inventoriés et contribuer au développement de la culture de tubercules d'igname. Toutefois de par le score pondéral de gravité très élevée $(3,32)$ des anomalies pluviométriques, une étude d'approfondissement des perceptions locales sur les variabilités climatiques et les pratiques locales de mitigation de leurs effets s'impose en culture d'igname au Togo. En plus l'étude d'un système innovant de gestion durable de la fertilité du sol et le contrôle des bioagresseurs est également une nécessité pour une gestion durable de la culture des ignames au Togo.

\section{References:}

1. Aboagye, L. M., Nyadanu, D., Opoku-Agyeman, M. O., Owusu S. K. \& Asiedu-Darko, E. (2015). Survey of diversity and production of yams in four communities in Southern Ghana. African Journal of Agricultural Research, 10: 2453-2459.

2. Adéwi, E., Badameli, K. M. S. \& Dubreuil, V. (2009). Influence de la péjoration pluviométrique sur les productions agricoles au Togo. Geographia technica, numéro spécial: 17-22.

3. Adéwi, E., Badameli, K. M. S. \& Dubreuil, V. (2010). Evolution des saisons de pluies potentiellement utiles au Togo de 1950 à 2000. Climatologie, 7 : 89-107.

4. Agbaje, G.O., Ogunsumi, L.O., Oluokun, J.A. \& Akinlosotu, T.A. (2005). Survey of yam production system and the impact of 
government policies in southwestern Nigeria. Journal of Food, Agriculture \& Environnement, 3: 222-229.

5. Alcouffe, S. (2002). «La diffusion de l'ABC en France : une étude empirique utilisant la théorie de la diffusion des innovations », Actes du $23^{\mathrm{e}}$ Congrès de l'AFC, Toulouse, France. $21 \mathrm{p}$.

6. Amar, A. (2014). Apport de la théorie des valeurs extrêmes à la modélisation et la gestion des risques boursiers, financiers et hydrométéorologiques. Thèse de Doctorat en mathématiques appliquées spécialité statistiques. Université Mohammed V-Agdal, Faculté des Sciences de Rabat. Maroc. 112p.

7. Andersson, I. \& Backlund, A. (2008). Structure and function of Rubisco. Plant Physiology and Biochemestry. 46:275-291.

8. Atato, A., Wala, K., Batawila, K., Woegan, A. Y. \& Akpagana, K. (2012). Diversité des fruitiers et ligneux spontanés du Togo. Diversity of edible wild fruit tree species of Togo. Correspondance et tirés-à-part; Fruits, EDP Sciences, 67: 353-368.

9. Ayisah, D.K. \& Gumedzoe, D.M.Y. (2012). Genetic diversity among yam mosaic virus (YMV) isolates infecting yam of the complex Dioscorea cayenensis- rotundata in Togo. International Journal of Biology and Chemical Scienses, 6: 1090-1101.

10. Ayisah, D.K., Banito, A. \& Gumedzoe, D.M.Y. (2014). Criblage de clones d'ignames du complexe Dioscorea cayenensis-rotundata pour la résistance au virus de la mosaïque de l'igname (YMV) au Togo. International Journal of Biology and Chemical Scienses, 8: 2198-2206.

11. Aziadekey, M., Sogbedji, M., Odah, K., Amouzouvi, K. \& Afanahin, K. (2014). Effets de la fumure organo-minérale sur la production et les qualités organoleptiques de deux variétés d'igname du complexe Dioscorea cayenensis-rotundata dans la région de la Kara au Togo. European Scientific Journal, 10: 178- 191.

12. Baco, M. N., Tostain, S., Mongbo, R. L., Daïnou, O. \& AAgbangla, C. (2004). Gestion dynamique de la diversité variétale des ignames cultivées (Dioscorea cayenensis-D. rotundata) dans la commune de Sinendé au nord Bénin. Plant Genetic Ressources Newsletter, N $^{\circ} 139$ : 18-24.

13. Baco, M.N., Moumouni, I., Saka, A.K., Dossou, R.A., Egah, J. \& Assiedu, E. (2013). De la gratuité à la marchandisation des semences d'igname au Bénin : quelles implications sur la sécurité alimentaire. $1^{\text {st }}$ conference of African research on agriculture, Food, and Nutrition, Yamoussoukro, Côte d'Ivoire.

14. Bricas, N. et Attaie, H. (1998). La consommation alimentaire des ignames Synthèse des connaissances et enjeux pour la recherche. In : 
L'igname, plante séculaire et culture d'avenir, Actes du séminaire international. MARCHAND J.-L. (Eds Cirad-Inra-Orstom-Coraf. 36 juin 1997, Montpellier, France. Pp21-30.

15. Chauvey, N. J. \& Naro, G. (2004). Les apports de l'ABC à l'analyse stratégique : les enseignements d'une recherche-intervention. Finance Contrôle Stratégie, 7: 63 - 89.

16. Dansi, A. \& Dantché, H. (2011). Rapport du projet: Increased farmers' and breeders' access to yam diversity in Togo. Global Crop Diversity Trust Q Foundation For Food Security. 111 p.

17. Dansi, A., Dantsey-Barry, H., Agré, A. P., Dossou-Aminon, I., Assogba, P., Loko, Y. L., N'Kpenu, E. K., Kombaté, K., Dansi, M. \& Vodouhè, R. (2013). Production constraints and farmers' cultivar preference criteria of cultivated yams (Dioscorea cayenensis - D. rotundata complex) in Togo. International Journal of Applied Biology and Pharmaceutical Technology. 4: 191-199.

18. Determine the root cause: 5 whys. iSixSigma-Editorial: ttps://www.isixsigma.com/tools-templates/cause-effect/determineroot-cause-5-whys/ consulté le 07/08/2019 à 17h28.

19. Dourma, M., Guelly, A. K., Kokou, K., Batawila, K., Wala, K., Bellefontaine, R. \& Akpagana, K. (2006). Multiplication par drageonnage d'Isoberlinia doka et I. tomentosa au sein des formations arborées du Nord-Togo. Bois et forêts des tropiques, Focus / Suckering. 289: 49-57.

20. Dourma, M., Batawila, K., Guelly, K. A., Bellefontaine, R., Foucault, B. D. \& Akpagana, K. (2012). La flore des forêts claires à Isoberlinia spp. en zone soudanienne au Togo. Acta Botanica Gallica, 159: 395-409.

21. Floquet, A. B., Maliki, R., Tossou, R. C. \& Tokpa, C. (2012). Évolution des systèmes de production de l'igname dans la zone soudano-guinéenne du Bénin. Cahiers Agricultures. 21: 427-37.

22. Floquet. A., Mongbo, R. L. \& Triomphe, B. (2015). Processus d'innovation en agriculture familiale au Bénin : une analyse des facteurs de succès et d'échec. AES, 5: 77-86.

23. Gubbels, P., Bandré, P., Batta, F. \& Lankouandé, F. (1998). Autodiagnostic organisationnel d'une nouvelle zone dans le cadre d'un programme d'appui visant le renforcement des capacités organisationnelles des communautés villageoises pour un processus efficace d'auto-développement. Guide méthodologique. Siège régionale Voisins Mondiaux. Ouagadougou. 37p.

24. Hahn, S.K. (1987). Yams, Dioscorea spp. (Dioscoreaceae). In N.W. Simmonds (eD.), Evolution of Crops Plants. London, pp. 112-120. 
25. Hahn, S.K. (1993). Lutte contre les maladies de l'igname. Guide de recherche de l'IITA $\mathrm{n}^{\circ}$ 39. Programme de la formation, Institut international d'agriculture tropicale. (IITA), Ibadan, Nigeria. 17 p.

26. Hardy, M. (2010). Pareto's law. Springer Science+Business Media, 32:38-39.

27. Hauser, T., Popilka, L., Hartl, F. U. \& Hayer-Hartl, M. (2015). Role of auxiliary proteins in Rubisco biogenesis and function. Review article. NATURE PLANTS DOI: 10.1038/NPLANTS2015.65. Www.nature.com/natureplants. 1: 1-11.

28. Institut Togolais de Recherche Agronomique (ITRA). (2007). Stratification du Togo en zones homogènes pour la recherche agronomique. Lomé. 104 p.

29. Lacointe, A., Zinsou, C. \& Constant, C. (1987). Effet de la date de plantation sur la croissance et le développement de plantules d'igname (Dioscorea alata L.) produites par culture in vitro. Agronomie, 7:475-481.

30. Mawussi, G. (2008). Bilan environnemental de l'utilisation de pesticides organochlorés dans les cultures de coton, café et cacao au Togo et recherche d'alternatives par l'évaluation du pouvoir insecticide d'extraits de plantes locales contre le scolyte du café (Hypothenemus hampei Ferrari). Thèse de Doctorat en sciences des agroressources, Institut National Polytechnique de Toulouse, France, 207 p.

31. Milano, (2015). Contribution des céréales et tubercules à la sécurité alimentaire et nutritionnelle des populations du Togo. Exposé thématique du Togo www.togopavillon.tg consulté le 07/08/2019 à 9h40.

Navia, D., Delgado, A., Viera, W., Báez, F. \& Trevor, J. (2017). Application of Bio-Products in Ecuadorian Agriculture: Case Banana. International Journal of Clinical and Biological Sciences, 2 : S7.

32. N'drin, O. J. A., Konan-Waidhet, A. B. \& Kienon-Kabore, T. H. (2019). Analyse des Déterminants de la Résilience aux changements climatiques des Cultivateurs du Département de Fresco, Côte d'Ivoire. European Scientific Journal. 15 :288-314.

33. Nicol, J.M., Turner, S.J., Coyne, D.L., Den Nijs, L., Hockland, S. \& Tahna Maafi, Z. (2011). Current nematode threats to world agriculture. In Genomics and Molecular Genetics of Plant-Nematode Interactions, Jones J, Gheysen G, Fenoll C (Eds). Springer: Heidelberg, Germany; 21-43. DOI: https://dx.doi.org/10.1007/97894-007-0434-3_2. 
34. Onkendi, E.M., Kariuki, G.M., Marais, M. \& Moleleki, L.N. (2014). The threat of root-knot nematodes (Meloidogyne spp.) in Africa: a review. Plant Pathology, 63: 727-737.

35. Ouédraogo, M. (2012). Impact des changements climatiques sur les revenus agricoles au Burkina Faso. Journal of Agriculture and Environment for International Development - JAEID, 106: 3 - 21.

36. Quénéhervé, P. (1997). Les nématodes de l'igname. In : L'igname plante séculaire et culture d'avenir, Actes du séminaire international Cirad-Inra-Orstom-Coraf. Montpellier, France. 3 - 6 juin 1997. pp 193-204.

37. Sandifer, ED. (2004). How Euler did it. Western Connecticut State University, Danbury, CT, USA. 3p.

38. Sikora, R.A. \& Fernández, E. (2005). Nematode parasites of vegetables. In Plant Parasitic Nematodes in Subtropical and Tropical Agriculture (2nd edn), Luc M, Sikora RA, Bridge J (eds). CABI Publishing: Wallingford; 319-392.

39. Soro, S., Diallo, A., H., Doumbia, M., Dao. D. \& Tano, Y. (2010). Inventaire des insectes de l'igname (Dioscorea spp): cas de Bouaké et Toumodi (Côte d'Ivoire). Journal of Animal \& Plant Sciences. 6: 715- 723.

40. Tournebize, R., Sierra, J., Bussière, F., Cinna J-P., Cornet, D., Kelemen, J-L. \& Osseux, J. (2012). Maîtrise de l'enherbement en culture d'ignames : intérêt de différents types de paillages. Journ'iames 2012, Journées Techniques sur les Ignames organisées par le centre INRA Antilles-Guyane et la Chambre d'Agriculture de Guadeloupe, 25 septembre et 2 octobre 2012, Petit Bourg et PetitCanal, Guadeloupe. Livre de recueil des textes des communications, pp 10-11.

41. Yao, K. F., Assiri, K. P., Seka, K. \& Diallo, A. H. (2017). Distribution et prévalence de l'anthracnose de l'igname dans quatre zones productrices de la Côte d'Ivoire. International Journal of Innovation and Applied Studies, 19:463-474. 